\title{
Vitamin D and colon cancer
}

Fábio Pereira, María Jesús Larriba and Alberto Muñoz*

Instituto de Investigaciones Biomédicas “Alberto Sols”, Consejo Superior de Investigaciones

Científicas - Universidad Autónoma de Madrid, Arturo Duperier 4, 28029 Madrid, Spain.

* Corresponding author:

Phone: \#34-91-5854451.Fax: \#34-91-5854401.E-mail: amunoz@iib.uam.es 


\begin{abstract}
The most active vitamin $\mathrm{D}$ metabolite, $1 \alpha, 25$-dihydroxyvitamin $\mathrm{D}_{3}\left(1,25(\mathrm{OH})_{2} \mathrm{D}_{3}\right)$, is a pleiotropic hormone with wide regulatory actions. Classically, vitamin D deficiency was known to alter calcium and phosphate metabolism and bone biology. In addition, recent epidemiological and experimental studies support the association of vitamin D deficiency with a large variety of human diseases, and particularly with the high risk of colorectal cancer. By regulating the expression of many genes via several mechanisms, $1,25(\mathrm{OH})_{2} \mathrm{D}_{3}$ induces differentiation, controls the detoxification metabolism and cell phenotype, sensitizes cells to apoptosis, and inhibits the proliferation of cultured human colon carcinoma cells. Consistently, $1,25(\mathrm{OH})_{2} \mathrm{D}_{3}$ and several of its analogues decrease intestinal tumourigenesis in animal models. Molecular, genetic, and clinical data in humans are scarce but they suggest that vitamin $\mathrm{D}$ is protective against colon cancer. Clearly, the available evidence warrants new, well-designed, large-scale trials to clarify the role of vitamin D in the prevention and/or therapy of this important neoplasia.
\end{abstract}

Keywords: vitamin $\mathrm{D}$, vitamin $\mathrm{D}$ target genes, $1 \alpha, 25$-dihydroxyvitamin $\mathrm{D}_{3}$, colon cancer 


\section{The vitamin D system}

Vitamin D belongs to a group of steroids with a broken ring known as secosteroids. The most important forms of vitamin $\mathrm{D}$ are vitamin $\mathrm{D}_{3}$ (cholecalciferol), produced in the human skin, and vitamin $\mathrm{D}_{2}$ (ergocalciferol), derived from plants (Horst et al. 2005). Nowadays, vitamin $\mathrm{D}_{3}$ is not categorized as a vitamin, but rather as a prohormone, given its synthesis in the skin and the multiple systemic actions of its metabolites.

The most active metabolite of vitamin $\mathrm{D}_{3}, 1 \alpha, 25$-dihydroxyvitamin $\mathrm{D}_{3}\left(1,25(\mathrm{OH})_{2} \mathrm{D}_{3}\right.$, calcitriol), is synthesized in a highly regulated multistep process. When human skin is exposed to sunlight, UV-B irradiation causes the photolysis of provitamin $\mathrm{D}_{3}$ (7dehydrocholesterol) to previtamin $\mathrm{D}_{3}$, a thermodynamically unstable isomer that is rapidly converted into vitamin $\mathrm{D}_{3}$. This passes into the bloodstream and is transported to the liver bound to the vitamin D binding protein (DBP, encoded by the $G C$ gene) and, to a lesser extent, to albumin. Alternatively, vitamin $\mathrm{D}_{3}$ can be absorbed in the intestine from dietary sources (Holick 2005; Norman 2008). Vitamin $\mathrm{D}_{3}$ is first hydroxylated in the liver by several mitochondrial and microsomal vitamin $\mathrm{D}_{3}$-25-hydroxylases. The resultant 25 -hydroxyvitamin $\mathrm{D}_{3}\left(25(\mathrm{OH}) \mathrm{D}_{3}\right.$, calcidiol) is the main circulating form of vitamin $\mathrm{D}_{3}$, and it is further hydroxylated in the kidney by mitochondrial $25(\mathrm{OH}) \mathrm{D}_{3}-1 \alpha$-hydroxylase (encoded by the gene CYP27B1), yielding the hormonally active form $1,25(\mathrm{OH})_{2} \mathrm{D}_{3}$ (Lamprecht and Lipkin 2003; Deeb et al. 2007). Importantly, CYP27B1 is also expressed in other human tissues and cell types, such as colon, brain, prostate, endothelial and immune cells, suggesting an extra-renal production of $1,25(\mathrm{OH})_{2} \mathrm{D}_{3}$ with paracrine/autocrine action (Townsend et al. 2005; Norman 2008; Norman and Bouillon 2010). The rate-limiting step in vitamin $\mathrm{D}_{3}$ metabolism is the transformation of $25(\mathrm{OH}) \mathrm{D}_{3}$ and $1,25(\mathrm{OH})_{2} \mathrm{D}_{3}$ to the less active compounds $24,25(\mathrm{OH})_{2} \mathrm{D}_{3}$ and $1,24,25(\mathrm{OH})_{3} \mathrm{D}_{3}$, respectively, through 24-hydroxylation by the ubiquitous CYP24A1 enzyme (Deeb et al. 2007). 


\section{Mechanism of action of $1 \alpha, 25$-dihydroxyvitamin $D_{3}$}

$1,25(\mathrm{OH})_{2} \mathrm{D}_{3}$ exerts its biological effects by binding to the vitamin $\mathrm{D}$ receptor (VDR), which is a member of the nuclear receptor superfamily of transcription factors and regulates gene expression in a ligand-dependent manner (Deeb et al. 2007; Thorne and Campbell 2008; Kim et al. 2009; Wu and Zhang 2009). VDR dimerizes with another member of the same family, the retinoid $\mathrm{X}$ receptor (RXR), whose ligand is 9-cis-retinoic acid or, at least in the mouse brain, docosahexaenoic acid (Heyman et al. 1992; Levin et al. 1992; de Urquiza et al. 2000). The VDR-RXR heterodimer binds to specific sequences of its target genes termed vitamin D response elements (VDREs). Curiously, studies on a few genes indicate a variable effect (additive, synergistic, or none) of 9-cis-retinoic acid on the action of $1,25(\mathrm{OH})_{2} \mathrm{D}_{3}$. Results from gel-shift and transactivation assays using DNA fragments close to transcription start sites (TSS) suggested that VDREs usually comprise two hexanucleotide direct repeats separated by three or four nucleotides (AGTTCAnnnAGTTCA, being $\mathrm{n}$ any nucleotide; DR3 or DR4) or two everted repeats interspaced by six to nine nucleotides (TGAACTnnnnnnAGTTCA; ER6-ER9) (Carlberg and Dunlop 2006; Carlberg and Seuter 2009).

However, this setting appears to be more complex in the light of the three chromatin immunoprecipitation sequencing (ChIP-Seq) studies published so far using human EpsteinBarr virus-transformed lymphoblastoid, THP-1 monocytic leukemia, and LS180 colon cancer cells (Ramagalopagan et al, 2010; Heikkinen et al., 2011; Meyer et al., 2012). Although performed in different cell types and using different duration and dose of $1,25(\mathrm{OH})_{2} \mathrm{D}_{3}$ treatment, these genome-wide studies coincide in concluding that there are hundreds $(623$, 520 , or 262, depending on the study) of genomic VDR binding sites in the absence of $1,25(\mathrm{OH})_{2} \mathrm{D}_{3}$, which increase to thousands $(2,776,1,820$ or 2,209$)$ after $1,25(\mathrm{OH})_{2} \mathrm{D}_{3}$ 
treatment. As expected due to the different conditions analyzed, only a few of the identified VDR binding sites overlap in the three studies (see also Carlberg et al., 2011). Common findings were also the presence of most VDR binding sites far from the TSS, the preference for the DR3-type in those located close to the TSS, and the shift from non-DR3 type to DR3type upon ligand activation (Carlberg et al., 2011; Meyer et al, 2012). These studies revealed that though the DR3-type is the most common VDR binding site, it represents less than $30 \%$ of all peaks, and that a high proportion of the peaks do not contain any classical VDRE. Very few genes have only one VDR binding site: more complex scenarios are common, such as genes with multiple VDR binding sites, two closely located target genes sharing one or more VDR binding sites, or even clusters of target genes, each containing each of them multiple VDR binding sites (Carlberg et al., 2011). In line with previous data, in LS180 cells RXR cooccupied a high proportion of VDR binding sites, which were most commonly of the DR3type (Meyer et al., 2012). Curiously, in this system, 1,073 (out of 1,674 ) $1,25(\mathrm{OH})_{2} \mathrm{D}_{3^{-}}$ induced VDR/RXR binding sites are located within repetitive DNA (Long Interdispersed Nuclear Elements, LINE) (Meyer et al., 2012). The characterization of the functional relevance of data from ChIP-Seq studies will require the combination with transcriptomic results and subsequent validation analyses.

The prevailing model for the mechanism of action of $1,25(\mathrm{OH})_{2} \mathrm{D}_{3} / \mathrm{VDR}$ predicts that, similarly to thyroid hormone and its receptors, in the absence of $1,25(\mathrm{OH})_{2} \mathrm{D}_{3}$ the VDR-RXR heterodimer is bound to VDREs and to transcriptional corepressors, such as nuclear corepressors (NCoRs) and the silencing mediator of retinoid and thyroid hormone receptors (SMRT), that recruit complexes with histone deacetylase (HDAC) activity and maintain the chromatin in a transcriptionally repressed state. In this model, $1,25(\mathrm{OH})_{2} \mathrm{D}_{3}$ binding to VDR induces conformational changes in VDR that cause the release of corepressors and binding of co-activators, such as steroid receptor co-activators (SRCs) and the CBP-p300 coregulator, 
and chromatin remodelers such as switch-sucrose non-fermenting (SWI-SNF), that acetylate nucleosome histones to untie DNA for transcription. Once the chromatin is derepressed, binding of the VDR-interacting protein 205 (DRIP205) to the VDR attracts other components of the DRIP-TRIP complex, which acts as a bridge with RNA polymerase II and the transcriptional machinery, thus permitting the initiation of transcription (Haussler et al. 1998; Deeb et al. 2007; Carlberg and Seuter, 2009; Pike and Meyer 2010).

The mechanism by which $1,25(\mathrm{OH})_{2} \mathrm{D}_{3}$ represses gene expression is less understood, although this process is probably equally important for its action, as around one-third of the target genes are inhibited (Pálmer et al. 2003; Heikkinen et al 2011). Several possibilities have been proposed, such as direct VDRE-dependent repression, competition for DNA binding between VDR and other transcription factors, or indirect repression via intermediate proteins (Kato et al. 2007; Kouzmenko et al. libro holick 2011). The best characterized transcriptional repression mechanism was elucidated for the $C Y P 27 B 1$ gene. In this case, the VDR-RXR heterodimer represses gene transcription in a $1,25(\mathrm{OH})_{2} \mathrm{D}_{3}$-dependent manner through E-box-type negative VDREs (nVDREs: CANNTG). When bound to nVDREs, the VDR-interacting repressor (VDIR, also known as TCF3 or E47) induces the transcriptional activation of the $C Y P 27 B 1$ gene. However, upon ligand binding VDR interacts with VDIR, promoting the dissociation of co-activators and the recruitment of corepressors and complexes with HDAC activity, which results in gene repression (Murayama et al. 2004; Kouzmenko et al. libro holick 2011).

Nongenomic actions of $1,25(\mathrm{OH})_{2} \mathrm{D}_{3}$ have also been described. They are rapid and transcription-independent effects that include the opening of ion channels and the activation or inhibition of kinases, phosphatases and phospholipases, and are probably relevant for the biological effects of $1,25(\mathrm{OH})_{2} \mathrm{D}_{3}$ (Norman et al. 2004 Nat Rev Drug Discovery; Haussler et al. 2011). Thus, in SW480-ADH colon cancer cells and in other cell types, $1,25(\mathrm{OH})_{2} \mathrm{D}_{3}$ 
causes a rapid increase in the cytosolic calcium concentration followed by the transient activation of the RhoA small GTPase, its effector ROCK and the p38MAPK and MSK-1 kinases that is required for the induction of its target genes (Ordóñez-Morán et al., 2008; Ordóñez-Morán et al., 2010). This shows the convergence of nongenomic and genomic $1,25(\mathrm{OH})_{2} \mathrm{D}_{3}$ effects, at least in this system (Ordóñez-Morán and Muñoz 2009).

\section{1 $\alpha, 25$-dihydroxyvitamin $D_{3}$ is a pleiotropic hormone}

The most widely and classically accepted physiological role for vitamin D, mediated mostly by $1,25(\mathrm{OH})_{2} \mathrm{D}_{3}$, is the regulation of calcium and phosphate homeostasis and bone mineralization (Holick 2007; Verstuyf et al. 2010). 1,25(OH) ${ }_{2} \mathrm{D}_{3}$ enhances intestinal calcium absorption in the small intestine and affects the absorption of dietary phosphate possibly by increasing its influx through the enterocyte brush border membrane (Ajibade et al. 2010). In concert with these effects, $1,25(\mathrm{OH})_{2} \mathrm{D}_{3}$ induces the maturation of preosteoclasts into osteoclasts, which remove calcium and phosphate from bone (Holick 2007; Verstuyf et al. 2010).

In the past decades, evidence has emerged that the importance of $1,25(\mathrm{OH})_{2} \mathrm{D}_{3}$ for health extends far beyond bone. The discovery in 1981 that $1,25(\mathrm{OH})_{2} \mathrm{D}_{3}$ induces the differentiation of myeloid leukemia cells and inhibits the growth of melanoma cells triggered the interest of cancer researchers (Abe et al. 1981; Colston et al. 1981). Since then, numerous observations have indicated a much broader range of action for $1,25(\mathrm{OH})_{2} \mathrm{D}_{3}$, including the regulation of cell differentiation, proliferation, apoptosis, invasion and angiogenesis in several types of tumour cells and animal models of cancer (Ordoñez-Moran et al 2005; Deeb et al 2007; Krishnan and Feldman 2011). These $1,25(\mathrm{OH})_{2} \mathrm{D}_{3}$ actions suggest a potential therapeutic role against hyperproliferative disorders such as cancer. Nevertheless, the use of $1,25(\mathrm{OH})_{2} \mathrm{D}_{3}$ is restricted by its hypercalcemic effect at therapeutic doses. This can be putatively overcome by 
the use of analogues that retain the antitumoural action but have less calcemic effect. Currently, there are numerous clinical trials ongoing using $1,25(\mathrm{OH})_{2} \mathrm{D}_{3}$ or its analogues, alone or in combination with other drugs, against several neoplasias (www.clinicaltrials.gov) (Deeb et al. 2007).

\section{Vitamin D and colon cancer: observational and epidemiological studies}

According to the International Agency for Research on Cancer (IARC) of the World Health Organization (WHO), about 12.7 million cancer cases and 7.6 million cancer deaths worldwide occurred in 2008. Colorectal cancer (CRC) is the third most frequent malignancy and the fourth leading cause of death from cancer worldwide, with 1,233,000 cases diagnosed and 608,000 deaths in 2008 .

The role of vitamin D in CRC prevention was first hypothesized by Frank and Cedric Garland based on ecological studies (Garland and Garland 1980). These authors proposed that the inverse relation between solar radiation (latitude) and CRC mortality and incidence in USA might be due to vitamin D synthesis. Later, the same authors reported an inverse association between vitamin D status and CRC in the USA (Garland et al. 1989). Since then, numerous studies have addressed the relationship between vitamin D status and colorectal adenoma and carcinoma incidence or mortality (Platz et al. 2000; Wu et al. 2007; Gandini et al. 2011). However, the integration and the overall analysis of all epidemiological studies is complex and thwarted by the fact that many of these studies do not take into account endogenous vitamin D production from sun exposure and are limited by measurement error from the various dietary assessment methods and food composition tables used to calculate dietary intake. Such limitations can be overcome by measuring circulating $25(\mathrm{OH}) \mathrm{D}$ concentration, a biomarker that provides an overall estimate of vitamin D status (both from endogenous production and from dietary intake). 
The substantial body of literature that examines the relationship between $25(\mathrm{OH}) \mathrm{D}$ level and CRC risk generally supports an inverse association. A prospective study in the USA with 16,818 participants found that CRC mortality was inversely related to serum $25(\mathrm{OH}) \mathrm{D}$ level (Freedman et al. 2007). A similar association was obtained in a case-control study that included an ethnically diverse population of Japanese, Latino, African-American, Caucasian and Native Hawaiian participants (Woolcott et al. 2010). Accordingly, a large observational nested case-control study (520,000 participants from 10 Western European countries) conducted within the European Prospective Investigation into Cancer and Nutrition concluded that there is a strong inverse association between $25(\mathrm{OH}) \mathrm{D}$ concentration and CRC (Jenab et al. 2010). A recent meta-analysis of 35 independent studies confirmed a consistent inverse relationship between serum 25(OH)D levels and CRC risk (Gandini et al. 2011). Ma et al. (Ma et al. JCO 2011) conducted a systematic review of 18 prospective studies assessing the association of vitamin D intake or serum levels of $25(\mathrm{OH}) \mathrm{D}$ and the risk of CRC in approximately 1,000,000 individuals and found an inverse correlation between CRC risk and both serum 25(OH)D and vitamin D intake.

Accepting the problems of using different approaches and techniques to measure vitamin D status, the population diversity and the potential presence of confounding factors, the consistency of the association between vitamin D status and CRC risk indicates a causal association (Giovannucci 2010). Accordingly, the IARC stated that the epidemiological evidence for a $\mathrm{r}$ between serum 25(OH)D levels and the incidence of CRC is consistent and persuasive. However, such a causal relationship awaits large, adequate prospective clinical trials (IARC 2008).

\section{Antitumoural actions of $1 \alpha, 25$-dihydroxyvitamin $D_{3}$ in colorectal cancer cells}


$\mathrm{CRC}$ arises as a consequence of the progressive accumulation of genetic and epigenetic alterations that induce the transformation and malignant progression of normal colonic epithelial cells. The initial genetic change in most colorectal adenomas, the earliest step in $\mathrm{CRC}$, is the somatic mutation in the tumour suppressor gene $A P C$ (or, to a lesser extent, AXIN2 or $C T N N B 1 / \beta$-catenin genes). Each of these mutually exclusive mutations leads to aberrant activation of the canonical Wnt/ $\beta$-catenin signalling pathway (Clevers 2006 Cell; Klaus and Birchmeier 2008 Nat Rev Cancer). In addition, a large proportion of adenomas carry activating mutations in $K-R A S$ or $B-R A F$, whereas inactivating mutations in the transforming growth factor (TGF)- $\beta$ pathway (mainly in $S M A D 2, S M A D 4$ or $T G F B R 2$ ) confer additional malignant features to adenoma cells (Markowitz and Bertagnolli 2009 NEJM). The inactivation of the TP53 tumour suppressor gene matches the adenoma-carcinoma transition in around 50\% of CRC tumours (Iacopetta 2003). The molecular mechanisms of carcinoma progression and the acquisition of metastatic ability remain to be fully elucidated, However, recent studies indicate that the epithelial-mesenchymal transition (EMT) endows epithelial cells with the capacity to invade the surrounding tissue and then to migrate to distant organs (Thiery et al. 2009; Chaffer and Weinberg 2011).

Numerous studies have shown that the antitumoural action of $1,25(\mathrm{OH})_{2} \mathrm{D}_{3}$ in $\mathrm{CRC}$ relies on several mechanisms at the cellular level, such as inhibition of cell proliferation, sensitization to apoptosis, induction of epithelial differentiation and cell detoxification metabolism, and inhibition of angiogenesis (Figure 1). The combined effect of these mechanisms, in a cell-type- and cell-context-dependent manner, may determine the antitumoural action of $1,25(\mathrm{OH})_{2} \mathrm{D}_{3}$ (Lamprecht and Lipkin 2003; Deeb et al. 2007; Larriba et al. 2008 Capitulo libro; Krishnan and Feldman 2011 Ann Rev Pharmacol Toxicol). A detailed list of the most important $1,25(\mathrm{OH})_{2} \mathrm{D}_{3}$ target genes in human CRC cells and their role in the antitumoural actions of the hormone is shown in Table 1. 


\section{Proliferation}

The growth-inhibitory effect of $1,25(\mathrm{OH})_{2} \mathrm{D}_{3}$ on $\mathrm{CRC}$ cells results from the accumulation of cells in the $\mathrm{G}_{0} / \mathrm{G}_{1}$ phase of the cell cycle. $1,25(\mathrm{OH})_{2} \mathrm{D}_{3}$ induces the expression of the cyclindependent kinase inhibitors $\mathrm{p} 21^{\mathrm{CIP} 1}$ and $\mathrm{p} 27^{\mathrm{KIP} 1}$, and represses that of cyclin $\mathrm{A}$ and cyclin $\mathrm{F}$ (Evans et al. 1999 Int J Oncol; Gaschott et al. 2002 BBRC; Pálmer et al. 2003; FernándezGarcía et al. 2005). A recent report by Liu et al. (Int J Cancer 2010) indicates that the induction of $\mathrm{p} 21^{\mathrm{CIP} 1}$ and the inhibition of proliferation by $1,25(\mathrm{OH})_{2} \mathrm{D}_{3}$ in $\mathrm{CRC}$ cell lines is dependent on the expression of the calcium-sensing receptor, which is in turn induced by $1,25(\mathrm{OH})_{2} \mathrm{D}_{3}$ (Chakrabarty et al., 2005). 1,25(OH) $)_{2} \mathrm{D}_{3}$ also induces the expression of the growth-arrest and DNA damage $45 \alpha(G A D D 45 A)$ gene (Pálmer et al. 2003), which is involved in cell cycle arrest after DNA damage and is required for the maintenance of genomic stability. In addition, $1,25(\mathrm{OH})_{2} \mathrm{D}_{3}$ regulates many other genes related to proliferation, including c-MYC, c-FOS and c-JUN (Pálmer et al. 2001; Pálmer et al. 2003; Meyer et al 2012 Mol Endocrinol). The $c-M Y C$ oncogene is deregulated and overexpressed in most cancers, and its downregulation by $1,25(\mathrm{OH})_{2} \mathrm{D}_{3}$ occurs directly, via multiple VDREs located in the promoter and intragenic regions, and indirectly, by increasing the expression and promoting the binding of intermediate proteins to regulatory regions of the gene (Pan Q et al. 1996 Endocrinology; Pan and Simpson 1999 J Biol Chem; Toropainen S et al. 2010 J Mol Biol; Meyer et al., 2011). As $c-M Y C$ is a target of the $\mathrm{Wnt} / \beta$-catenin pathway, another indirect mechanism of downregulation of this gene by $1,25(\mathrm{OH})_{2} \mathrm{D}_{3}$ is the antagonism of this pathway (Pálmer et al. 2001; discussed below). 
Apoptosis sensitization by $1,25(\mathrm{OH})_{2} \mathrm{D}_{3}$ in colorectal adenoma and carcinoma cells involves the upregulation of the pro-apoptotic protein BAK and the downregulation of the nuclear antiapoptotic protein BAG-1 (Díaz et al. 2000; Barnes et al. 2005). The effect of $1,25(\mathrm{OH})_{2} \mathrm{D}_{3}$ on the expression of other pro-apoptotic $(\mathrm{BAX})$ or anti-apoptotic $\left(\mathrm{BCL}-2, \mathrm{BCL}-\mathrm{X}_{\mathrm{L}}\right)$ proteins, which are regulated by $1,25(\mathrm{OH})_{2} \mathrm{D}_{3}$ in other cell systems, is not clear in CRC, and appears to be cell-specific (Díaz et al. 2000; Hansen et al. 2001). In addition, $1,25(\mathrm{OH})_{2} \mathrm{D}_{3}$ induces the expression of G0S2 (Pálmer et al. 2003), a mitochondrial protein that interacts with BCL-2 and induces apoptosis in CRC cells by preventing BCL-2 from forming anti-apoptotic heterodimers with BAX (Welch C et al. 2009 Cancer Res). Although previous reports indicated that the apoptosis potentiated by $1,25(\mathrm{OH})_{2} \mathrm{D}_{3}$ does not require an intact TP53 tumour suppressor gene (Díaz et al. 2000; Hansen et al. 2001), a recent study by Stambolsky et al. (Cancer Cell 2010) has revealed that mutant p53 protein interacts with VDR and modulates the transcriptional activity of $1,25(\mathrm{OH})_{2} \mathrm{D}_{3}$ leading to the increase of the expression of survival-promoting genes and the decrease of that of pro-apoptotic genes, thus converting $1,25(\mathrm{OH})_{2} \mathrm{D}_{3}$ into an anti-apoptotic agent. In CRC cells, $1,25(\mathrm{OH})_{2} \mathrm{D}_{3}$ promotes sensitivity to the chemotherapeutic agent 5-fluorouracil by downregulating the expression and the transcriptional activity of survivin, an anti-apoptotic protein, and that of thymidylate synthase, an enzyme involved in DNA de novo synthesis and the molecular target of 5-fluorouracil (Liu G et al. 2010 Int J Cancer). Moreover, in an in vitro model developed to evaluate the crosstalk between tumour-associated macrophages and CRC cells, $1,25(\mathrm{OH})_{2} \mathrm{D}_{3}$ restores the sensitivity of CRC cells to TRAIL-induced apoptosis by interfering with the release of IL-1 $\beta$ by macrophages (Kaler et al. 2010 Plos One).

\section{Differentiation}


$1,25(\mathrm{OH})_{2} \mathrm{D}_{3}$ has specific and multiple prodifferentiation effects in CRC cells. It increases the expression and/or activity of several brush border enzymes, such as alkaline phosphatase and maltase, and enhances the formation of microvilli (Brehier and Thomasset $1988 \mathrm{~J}$ Steroid Biochem; Giuliano AR et al. 1991 Arch Biochem Biophys; Halline AG et al. 1994; Díaz et al. 2000). In addition, $1,25(\mathrm{OH})_{2} \mathrm{D}_{3}$ increases the expression of several components of cell adhesion structures that are essential for the maintenance of the epithelial phenotype: (i) occludin, zonula occludens (ZO)-1 and -2, and claudin-2 and -12 in tight junctions (Pálmer et al. 2001; Fujita H 2008 Mol Biol Cell); (ii) E-cadherin in adherens junctions (Pálmer et al. 2001); and (iii) plectin in hemidesmosomes (Pálmer et al. 2003). Moreover, $1,25(\mathrm{OH})_{2} \mathrm{D}_{3}$ induces the expression of components or proteins associated with the actin cytoskeleton and intermediate filaments such as keratin-13, vinculin, and filamin A (Pálmer et al. 2001; Pálmer et al. 2003). Filamin A has been implicated in cell motility, adhesion, and invasion (Nakamura et al. Cell Adh Migr 5, 160-169, 2011). However, novel functions of filamin A have recently been described within the cell nucleus, such as the regulation of nuclear shape during EMT and of DNA double-strand break repair (Yue J, Wang Q et al. 2009 Cancer Res; Gay O et al 2011 PNAS).

\section{Angiogenesis}

The angiogenic capacity of CRC cells may be affected by $1,25(\mathrm{OH})_{2} \mathrm{D}_{3}$, as it represses the expression and transcriptional activity of hypoxia-inducible factor (HIF)-1, a key transcription factor involved in hypoxia-induced angiogenesis (Ben-Shoshan et al. 2007 Mol Cancer Ther). In addition, $1,25(\mathrm{OH})_{2} \mathrm{D}_{3}$ regulates the expression of vascular endothelial growth factor (VEGF) and thrombospondin-1 (TSP-1), two major opposing factors that control tumour angiogenesis, leading to a balanced change in the angiogenic potential of SW480-ADH cells (Fernández-García et al. 2005). Further, $1,25(\mathrm{OH})_{2} \mathrm{D}_{3}$ strongly represses DICKKOPF-4 
(DKK-4), a weak Wnt antagonist that promotes invasion and angiogenesis in cultured CRC cells and is upregulated in colon tumours (Pendás-Franco et al. 2008).

\section{Detoxification}

Intestinal epithelial cells express a variety of enzymes involved in the detoxification and metabolism of xenobiotics from dietary sources and of deleterious endobiotic compounds that may contribute to CRC development. Phase I enzymes, most of which belong to the cytochrome P450 (CYP) superfamily, initiate the enzymatic detoxification of these compounds by oxidation, hydrolysis or reduction (Kaminsky and Zhang 2003 Drug Metab Dispos). In CRC cells, $1,25(\mathrm{OH})_{2} \mathrm{D}_{3}$ induces the expression of CYP3A4, the member of the CYP superfamily most expressed in the intestine (Thummel et al. 2001 Mol Pharmacol; Thompson et al. 2002 Biochem Biophys Res Com; Pfrunder A et al. $2003 \mathrm{~J}$ Pharm Pharmacol). Likewise, several members of the CYP2C subfamily contain VDREs in their promoters and are regulated by $1,25(\mathrm{OH})_{2} \mathrm{D}_{3}$ in hepatic tissues. As CYP2C is the second most abundant CYP subfamily in the human intestine, its putative regulation by $1,25(\mathrm{OH})_{2} \mathrm{D}_{3}$ in the intestine could be highly relevant (Drocourt L et al. 2002 J Biol Chem; Chen and Goldstein 2009 Curr Drug Metab).

Phase II enzymes conjugate different charged groups to the compounds previously modified by phase I enzymes, which increases their solubility in water and facilitate their excretion (Kaminsky and Zhang 2003 Drug Metab Dispos). In CaCo-2 cells, 1,25(OH) $)_{2} \mathrm{D}_{3}$ activates the transcription of SULT2A1, a phase II sulphotransferase that acts preferentially on hydroxysteroids and cholesterol-derived sterol bile acids, but may also modify several drugs and other xenobiotics (Echchgadda I et al. 2004 Mol Pharmacol).

In addition, $1,25(\mathrm{OH})_{2} \mathrm{D}_{3}$ regulates the expression of several transporters responsible for the efflux of phase II conjugates to the extracellular medium. One of them is the drug efflux 
pump multidrug resistance protein (MDR)-1, which is located in the enterocyte apical membrane (Pfrunder A et al. 2003 J Pharm Pharmacol; Aiba T et al. 2005 Drug Metab Pharmacokinet, Fan et al. $2009 \mathrm{~J}$ Pharmacol Exp Ther). 1,25(OH $)_{2} \mathrm{D}_{3}$ also modulates the expression of members of the multidrug resistance-associated protein (MRP) family, which are involved in the transport of conjugated and unconjugated bile acids, and also in that of glutathione and sulphate conjugates (McCarthy et al. 2005 J Biol Chem; Fan et al. 2009 J Pharmacol Exp Ther).

Thus, $1,25(\mathrm{OH})_{2} \mathrm{D}_{3}$ has a wide-ranging effect on the expression of several proteins involved in intestinal detoxification, which is consistent with a preventive and therapeutic action of this hormone against CRC.

\section{Interference with the Wnt/ $\beta$-catenin pathway and interplay with other signalling pathways} $1,25(\mathrm{OH})_{2} \mathrm{D}_{3}$ interferes with several signalling pathways, which may partially mediate its antitumoural effects. Results from our group and others have demonstrated that $1,25(\mathrm{OH})_{2} \mathrm{D}_{3}$ inhibits the Wnt/ $\beta$-catenin pathway and the activation of its target genes in CRC cells, which contributes to the inhibition of cell proliferation and to the maintenance of the differentiated phenotype (Pálmer et al., 2001; González-Sancho et al. libro vitD 2011 Feldman, review). $1,25(\mathrm{OH})_{2} \mathrm{D}_{3}$ inhibits the $\mathrm{Wnt} / \beta$-catenin pathway through several mechanisms. First, it rapidly increases the amount of VDR bound to $\beta$-catenin, thus reducing the interaction between $\beta$ catenin and the transcription factors of the TCF/LEF family and leading to the repression of its target genes (Pálmer et al. 2001). Shah et al. (2006) confirmed the VDR/ $\beta$-catenin interaction and characterized the protein domains involved, while Egan et al. (2010) reported that wild-type APC enhances the inhibition of $\beta$-catenin/TCF transcriptional activity by $1,25(\mathrm{OH})_{2} \mathrm{D}_{3}$. Second, $1,25(\mathrm{OH})_{2} \mathrm{D}_{3}$ induces $\beta$-catenin nuclear export linked to E-cadherin accumulation at the plasma membrane adherens junctions (Pálmer et al. 2001). Third, it 
induces the expression of DKK-1, an extracellular Wnt inhibitor (Aguilera et al. 2007). In addition, $1,25(\mathrm{OH})_{2} \mathrm{D}_{3}$ impedes the production of IL-1 $\beta$ by THP-1 monocytic leukemia cells and, if extrapolated to tumour-associated macrophages, this would represent another mechanism of inhibition of $\beta$-catenin/TCF-dependent gene activation in CRC cells, as IL-1 $\beta$

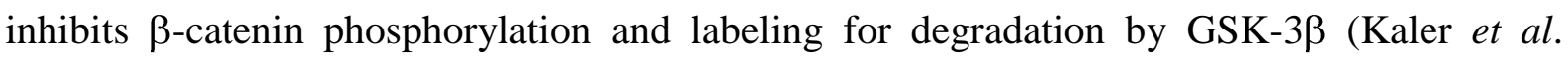
Oncogene 2009). Thus, $1,25(\mathrm{OH})_{2} \mathrm{D}_{3}$ exerts a complex set of regulatory actions leading to the inhibition of the $W n t / \beta$-catenin pathway. As this pathway is aberrantly activated in most adenomas and colorectal tumours and is considered the main driving force in this neoplasia, its inhibition is probably crucial for the antitumoural action of $1,25(\mathrm{OH})_{2} \mathrm{D}_{3}$ in CRC.

Additionally, $1,25(\mathrm{OH})_{2} \mathrm{D}_{3}$ sensitizes $\mathrm{CRC}$ cells to the growth inhibitory action of TGF- $\beta$ by upregulating the expression of its type I receptor (TGFBR1) (Chen et al. 2002). Moreover, $1,25(\mathrm{OH})_{2} \mathrm{D}_{3}$ inhibits the stimulation of cell proliferation by epidermal growth factor (EGF) via the reduction of EGF receptor (EGFR) expression and the induction of its internalization upon ligand binding (Tong et al. 1999). 1,25(OH) $)_{2} \mathrm{D}_{3}$ may also inhibit EGFR activity by inducing the expression of E-cadherin (Pálmer et al 2001) and by repressing that of SPROUTY-2 (Barbáchano et al 2010, see below), which are respectively negative and positive regulators of EGFR activity (Andl CD and Rustgi AK 2005 Cancer Biol Ther, Cabrita and Christofori 2008). Likewise, $1,25(\mathrm{OH})_{2} \mathrm{D}_{3}$ interferes with the growth-stimulatory effect of insulin growth factor (IGF)-II through the inhibition of IGF-II secretion and the modulation of the expression of several genes encoding IGF binding proteins (IGFBP) (Oh et al. 2001, Pálmer et al. 2003).

\section{1 $\alpha, 25$-dihydroxyvitamin $\mathrm{D}_{3}$ target genes in colorectal cancer cells}

The development of high-throughput techniques for gene expression profiling, such as microarrays, has allowed a more detailed study of $1,25(\mathrm{OH})_{2} \mathrm{D}_{3}$ effects in the transcriptome of 
cancer cells (reviewed in Kriebitzsch et al. 2009 Anticancer Res). We and others (Pálmer 2003; Wood et al. 2004 Physiol Genomics) performed oligonucleotide microarrays in CRC cells treated with $1,25(\mathrm{OH})_{2} \mathrm{D}_{3}$. Our results showed that around two thirds of $1,25(\mathrm{OH})_{2} \mathrm{D}_{3}$ target genes are upregulated, while a third of these genes are downregulated after $1,25(\mathrm{OH})_{2} \mathrm{D}_{3}$ treatment. A high proportion of the regulated genes are related to transcription, cell adhesion and metabolism, although genes related to many different cell functions were also found (Pálmer et al 2003). In the past decade, our laboratory has dedicated much effort to characterizing the role of several of these genes in the antitumoral action of $1,25(\mathrm{OH})_{2} \mathrm{D}_{3}$ in CRC.

One of the genes regulated by $1,25(\mathrm{OH})_{2} \mathrm{D}_{3}$ in our transcriptomic analysis was CST5, encoding cystatin D, an inhibitor of cysteine proteases of the cathepsin family. We validated the strong induction of cystatin $\mathrm{D}$ by $1,25(\mathrm{OH})_{2} \mathrm{D}_{3}$ and found that it mediates the antiproliferative and prodifferentiation effects of $1,25(\mathrm{OH})_{2} \mathrm{D}_{3}$ in CRC cells (Álvarez-Díaz et al 2009). Cystatin D regulation by $1,25(\mathrm{OH})_{2} \mathrm{D}_{3}$ also occurs in xenografted mice treated with the $1,25(\mathrm{OH})_{2} \mathrm{D}_{3}$ analogue EB1089/Seocalcitol, and a direct correlation between cystatin D and VDR protein levels was observed in human CRC biopsies, suggesting that $1,25(\mathrm{OH})_{2} \mathrm{D}_{3}$ also regulates cystatin D in vivo (Álvarez-Díaz et al 2009). In addition, ectopic cystatin D inhibits proliferation, migration and anchorage-independent growth of cultured CRC cells and growth of xenografted tumours in mice. Moreover, cystatin D expression is downregulated during colorectal tumourigenesis and is associated with tumour dedifferentiation. All together, these data led us to propose CST5 as a candidate tumour suppressor gene in CRC (ÁlvarezDíaz et al 2009). The mechanism by which this protease inhibitor mediates its actions is not fully understood. Experiments using mutant cystatin D proteins with reduced antiproteolytic activity indicate that at least some of its antitumour effects may be independent of cathepsin inhibition (Álvarez-Díaz et al 2009). In line with this, $1,25(\mathrm{OH})_{2} \mathrm{D}_{3}$ regulates a number of 
genes related to the protein degradation machinery, such as proteases, other protease inhibitors, and components of the ubiquitin-proteasome system (Álvarez-Díaz et al. 2010 Cell Cycle).

$S P R Y-2$ is another gene shown by transcriptomic assays to be regulated by $1,25(\mathrm{OH})_{2} \mathrm{D}_{3}$ (5.6-fold repression at $4 \mathrm{~h}$ of treatment) (Pálmer et al., 2003). SPRY-2 encodes SPROUTY-2, an intracellular modulator of EGFR and other growth factor tyrosine kinase receptors involved in the regulation of cell growth, migration and angiogenesis (Cabrita and Christofori, 2008). SPROUTY-2 strongly inhibits the intercellular adhesion induced by $1,25(\mathrm{OH})_{2} \mathrm{D}_{3}$, and gain- and loss-of-function experiments showed that SPROUTY-2 and E-cadherin repress reciprocally in CRC cell lines and have opposite actions on cell differentiation (Bárbachano et al. 2010). Accordingly, the expressions of SPROUTY-2 and E-cadherin are mutually exclusive in xenografted tumours and correlate inversely in human CRC biopsies, where SPROUTY-2 is upregulated in undifferentiated high-grade tumours and at the invasive front of low-grade carcinomas (Barbáchano et al., 2010). Therefore, SPROUTY-2 is inhibited by $1,25(\mathrm{OH})_{2} \mathrm{D}_{3}$ and is a potential novel marker of malignancy and a pharmacological/therapeutic target in CRC.

Several candidate $1,25(\mathrm{OH})_{2} \mathrm{D}_{3}$ target genes encode for proteins implicated in epigenetic regulation of gene expression. We have recently reported that $1,25(\mathrm{OH})_{2} \mathrm{D}_{3}$ induces the expression of the JMJD3 gene (Pereira et al. 2011), which codes for a histone demethylase of the tri-methyl repressive mark on lysine 27 of histone $\mathrm{H} 3$, and which may have an important tumour suppressor function (De Santa et al 2007; Agger et al 2009). JMJD3 partially mediates the prodifferentiation, antiproliferative and gene regulatory actions of $1,25(\mathrm{OH})_{2} \mathrm{D}_{3}$, and also its antagonism of the $\mathrm{Wnt} / \beta$-catenin pathway (Pereira et al. 2011). Moreover, JMJD3 depletion upregulates the expression of EMT inducers and mesenchymal markers, while it downregulates that of epithelial proteins. Importantly, and in line with data in cultured cells, 
the expression of JMJD3 RNA was lower in tumour tissue than in normal tissue in a $56 \%$ of human colorectal tumours and directly correlates with that of VDR (Pereira et al. 2011). Recent data indicate that $1,25(\mathrm{OH})_{2} \mathrm{D}_{3}$ modulates the expression of several genes coding for histone demethylases of the Jumonji $\mathrm{C}$ domain and lysine-specific demethylase families (Pereira et al. 2011 in press/submitted). These findings link chromatin epigenetic regulation with the transcriptional activity of $1,25(\mathrm{OH})_{2} \mathrm{D}_{3}$.

The new generation of ChIP-Seq studies mentioned mentioned are expected to contribute to our understanding of $1,25(\mathrm{OH})_{2} \mathrm{D}_{3}$ actions on a genome-wide scale, and to the identification of its target genes. In their work, Meyer et al. (2012) report new genes activated by $1,25(\mathrm{OH})_{2} \mathrm{D}_{3}$ in $\mathrm{LS} 180$ colon cancer cells, such as several members of the peptidylarginine deiminase family, a class of enzymes that convert histone methylated residues of arginine to citrulline (Klose and Zhang 2007), thus expanding the number of epigenetic modifiers that are regulated by $1,25(\mathrm{OH})_{2} \mathrm{D}_{3}$ in CRC cells.

Proteomic approaches have also identified $1,25(\mathrm{OH})_{2} \mathrm{D}_{3}$-regulated proteins in CRC cells. Our laboratory has used 2D-DIGE electrophoresis combined with MALDI-TOF-TOF mass spectrometry to identify nuclear proteins regulated by $1,25(\mathrm{OH})_{2} \mathrm{D}_{3}$ in $\mathrm{SW} 480-\mathrm{ADH}$ cells (Cristobo et al. $2011 \mathrm{~J}$ Prot). Interestingly, several of these proteins are involved in the regulation of the spliceosome machinery, suggesting a role of $1,25(\mathrm{OH})_{2} \mathrm{D}_{3}$ in alternative splicing, which is frequently altered in cancer (Miura K et al 2011 Cancer Sci; David and Manely 2011 Genes Dev). In addition, $1,25(\mathrm{OH})_{2} \mathrm{D}_{3}$ also regulates the expression of a few cytoskeletal and actin-binding proteins (ezrin, radixin, coronin 1C), some of which perform transcription-related functions in the cell nucleus in addition to modulating cell morphology and adhesion (Cristobo et al. $2011 \mathrm{~J}$ Prot).

\section{Mechanisms of resistance to $1 \alpha, 25$-dihydroxyvitamin $D_{3}$ action in colorectal cancer}


CRC cell responsiveness to $1,25(\mathrm{OH})_{2} \mathrm{D}_{3}$ depends mainly on the expression of VDR and on the bioavailability of $1,25(\mathrm{OH})_{2} \mathrm{D}_{3}$ within the cell. The intracellular level of $1,25(\mathrm{OH})_{2} \mathrm{D}_{3}$ is determined by the circulating levels of $25(\mathrm{OH}) \mathrm{D}_{3}$ and $1,25(\mathrm{OH})_{2} \mathrm{D}_{3}$, and by the activity of CYP27B1 and CYP24A1 within the cell. CYP27B1 expression and activity are upregulated at early stages of colorectal tumourigenesis and drastically decreased in advanced CRC, while those of CYP24A1 are overexpressed in colorectal carcinomas. These changes lead to attenuated $1,25(\mathrm{OH})_{2} \mathrm{D}_{3}$ synthesis and accelerated $1,25(\mathrm{OH})_{2} \mathrm{D}_{3}$ catabolism in advanced $\mathrm{CRC}$, causing resistance to $1,25(\mathrm{OH})_{2} \mathrm{D}_{3}$ (Bareis et al 2001 Biochem Biophys Res Commun; Cross et al 2001 Steroids; Bises et al 2004 J Histochem Cytochem).

Several studies have shown that VDR is expressed by normal and certain tumour colon epithelial cells (Sheinin 2000 Virchows Arch; González-Sancho et al 2006; Modica S Gastroenterology 2010) and is associated with a high degree of cell differentiation (Zhao and Feldman 1993 Endocrinology; Shabahang M et al. 1993 Cancer Res). VDR expression is enhanced in early stages of colorectal tumourigenesis (adenomas, polyps), whereas it decreases in advanced stages (Sheinin 2000 Virchows Arch; Cross HS et al 2001; Larriba and Muñoz 2005; Matusiak et al. 2005; Anderson et al 2006). Accordingly, elevated VDR expression is associated with high tumour differentiation, absence of node involvement, and good prognosis in CRC (Cross HS et al 1996; Evans et al 1998).

VDR downregulation causes unresponsiveness to $1,25(\mathrm{OH})_{2} \mathrm{D}_{3}$ and failure of the therapy with $1,25(\mathrm{OH})_{2} \mathrm{D}_{3}$ or its analogues. For this reason, our group has searched for mechanisms to explain the loss of VDR in advanced CRC. We found that SNAIL1, a repressor of E-cadherin and a strong EMT inducer, represses the expression of VDR and blocks $1,25(\mathrm{OH})_{2} \mathrm{D}_{3}$ antitumoural actions in CRC cells in culture and such cells xenografted in mice (Palmer et al 2004; Larriba et al 2007). Additionally, SNAIL1 is upregulated in approximately $60 \%$ of colorectal tumours and is associated with VDR downregulation (Pálmer et al 2004; Peña et al 
2005; Peña et al 2006). In addition to SNAIL1, its family member SNAIL2 (but not other EMT inducers such as ZEB1, ZEB2, TWIST1 or E47) also represses VDR expression and blocks $1,25(\mathrm{OH})_{2} \mathrm{D}_{3}$ action in CRC cells (Larriba et al 2009). Moreover, SNAIL1 and SNAIL2 show an additive repressive effect on VDR expression in cultured cells and in colorectal tumours (Larriba et al 2009; Larriba et al 2010 JSMB). Thus, it is likely that efficient VDR repression during CRC progression requires the expression of both SNAIL1 and SNAIL2, and that their expression in colorectal tumours could be used to identify patients who are likely to benefit from therapy with $1,25(\mathrm{OH})_{2} \mathrm{D}_{3}$ or its analogues.

\section{Antitumoural action of vitamin D in animal models of colorectal cancer}

Results obtained in several types of studies using experimental animals support a protective and therapeutic action of vitamin D against CRC. Administration of a western-style diet (high in fat and low in vitamin D and calcium) generates colonic crypt hyperplasia and colon dysplasia in wild-type mice, and increases the incidence of preneoplastic lesions in various preclinical mouse models of intestinal tumourigenesis. These effects are suppressed upon diet supplementation with calcium and vitamin D (reviewed in Lamprecht and Lipkin 2003, Ordóñez-Morán et al 2005).

Human tumour cells implanted subcutaneously into immunosuppressed mice (xenografts) are commonly used as an in vivo approach in preclinical anticancer drug development. Numerous studies have shown that $1,25(\mathrm{OH})_{2} \mathrm{D}_{3}$ and several analogues clearly reduce the growth of colorectal xenografts (reviewed in Ordóñez-Morán et al. 2005; Deeb et al. 2007; Kang et al. 2011 World J Gastro Oncology). Similar results were obtained using different chemical carcinogens (N-methyl-N-nitrosourea, azoxymethane and others) to generate colorectal tumours in mice or rats. The number of tumours generated after chronic treatment 
with the carcinogens was reduced by the administration of $1,25(\mathrm{OH})_{2} \mathrm{D}_{3}$ or several of its analogues (reviewed in Ordóñez-Morán et al., 2005).

Both $1,25(\mathrm{OH})_{2} \mathrm{D}_{3}$ and its less calcemic derivative 1,25(OH)$)_{2}$-16-ene-19-nor-24-oxo- $\mathrm{D}_{3}$ reduce tumour load (the sum of all polyp areas) in $A p c^{\mathrm{min} /+}$ mice, a mouse model of intestinal carcinogenesis that carries a mutated allele of the tumour suppressor gene Apc and spontaneously develops multiple neoplasias throughout the intestinal tract. Xu et al. (2010) confirmed these results and also found that treatment with $1,25(\mathrm{OH})_{2} \mathrm{D}_{3}$ or two of its analogues increases the expression of E-cadherin, inhibits that of c-myc and reduces $\beta$-catenin nuclear levels in the small intestine and colon of $A p c^{\mathrm{min} /+}$ mice. However, a recent study by Irving et al. (2011) has shown that treatment with $25(\mathrm{OH}) \mathrm{D}_{3}$ or two $1,25(\mathrm{OH})_{2} \mathrm{D}_{3}$ analogues did not affect intestinal tumour development in the $A p c^{\mathrm{Pirc} /+}$ rat or in the $A p c^{\mathrm{min} /+}$ mouse models in the absence or in the presence of the colonic tumour inducer dextran sodium sulphate (Irving et al. 2011). As the authors comment, it is however possible that the length of treatment with the vitamin $\mathrm{D}$ compounds, or the putative loss of $V d r$ expression in the tumours might have influenced the results of the study (Irving et al. 2011).

Genetically-modified mice have also been used to study the effects of the disruption of VDR expression on colorectal tumourigenesis. $V d r$-deficient mice do not show a spontaneous increase in cancer but are more prone to oncogene- or carcinogen-induced tumours (Bouillon et al. 2008 Endocr Rev). These animals display colonic crypt hyperproliferation, and increased levels of DNA damage and oxidative stress in the intestine (Kallay E et al 2001 Carcinogenesis; Kallay E et al 2002 Food Chem Toxicol). Recently, two teams have bred $V d r^{-}$ ${ }^{/+}$and $\mathrm{Apc}^{\mathrm{min} /+}$ mice in order to evaluate the consequences of $\mathrm{Vdr}$ deficiency on the initiation and development of intestinal cancer (Larriba et al., 2011; Zheng et al., 2011). These studies described increased tumour burden in $V d r^{-/-} A p c^{\mathrm{min} /+}$ mice as compared to $V d r^{+/+} A p c^{\mathrm{min} /+}$. 
Importantly, $V d r^{-/-} A p c^{\mathrm{min} /+}$ mice also show higher activation of the $\mathrm{Wnt} / \beta$-catenin pathway and an increase in the number of colonic aberrant crypt foci (Larriba et al., 2011).

\section{Human studies: clinical and molecular data}

Few large-scale cancer intervention trials on vitamin D treatment in human CRC patients have been reported. The first of these was a randomized, double-blind, placebo-controlled trial of 2,686 individuals (65-85 $\mathrm{yr}$ of age) receiving $100,000 \mathrm{IU}$ vitamin $\mathrm{D}_{3}$ or placebo every 4 months ( $\sim 833 \mathrm{IU} / \mathrm{d})$. This study did not find any significant effect of vitamin $\mathrm{D}_{3}$ supplementation on CRC incidence or mortality after 5 years (Trivedi et al. 2003 BMJ). Accordingly, another randomized, double-blinded, placebo-controlled trial performed by the US Women's Health Initiative, including 36,282 postmenopausal women (50-79 yr of age) who were treated with $400 \mathrm{IU} / \mathrm{d}$ vitamin $\mathrm{D}_{3}+1 \mathrm{~g} / \mathrm{d}$ calcium $v$ s placebo, failed to find any effect of the treatment on CRC incidence (Wactawski-Wende et al. New England J Med 2006). However, the study had serious drawbacks that challenge its validity: the low amount of vitamin $\mathrm{D}_{3}$ used did not increase the circulating $25(\mathrm{OH}) \mathrm{D}_{3}$ levels, the degree of patient adherence to the treatment was low, and the follow-up period was short (7 years) (WactawskiWende et al. New England J Med, 2006). Still, re-analysis of the data showed that concurrent estrogenic therapy increased CRC risk and that the treatment with vitamin $\mathrm{D}_{3}+$ calcium was beneficial in its absence (relative risk, RR 0.71; 95\% confidence interval, 95\% CI 0.46-1.09) (Ding et al. Int J Cancer 2008). The third study with published results was a smaller trial performed in Nebraska (USA) with 1,179 postmenopausal women (mean age $67 \mathrm{yr}$ ) who were treated with $1,100 \mathrm{IU} / \mathrm{d}$ vitamin $\mathrm{D}_{3}+1.4-1.5 \mathrm{~g} / \mathrm{d}$ calcium $v s$ calcium alone for 4 years (Lappe et al. 2007 Am J Clin Nutr). Treatment with vitamin $\mathrm{D}_{3}+$ calcium reduced total cancer incidence (RR 0.40; 95\% CI 0.20-0.82), including CRC, particularly if the first-year cases 
were not considered. However, the low number of CRC cases reduces the validity of the study (Lappe et al. 2007 Am J Clin Nutr).

At the molecular level, Holt et al. (2006) showed that combined daily supplementation of 11 patients with vitamin $\mathrm{D}_{3}(400 \mathrm{IU})$ and calcium $(1.5 \mathrm{~g})$ for six months reduced the proliferation of colonic flat mucosa and polyps, increased the expression of BAK and diminished that of the CRC-associated mucin MUC5AC when compared to the placebo group (8 patients). In a series of recent papers, Fedirko et al. reported that $800 \mathrm{IU} / \mathrm{d}$ vitamin $\mathrm{D}_{3}$ and/or $2 \mathrm{~g} / \mathrm{d}$ calcium (in 92 patients with at least one adenoma, six months treatment) increased BAX and $\mathrm{p} 21^{\mathrm{CIP} 1}$ expression in colorectal crypts (Fedirko et al Cancer Prev Res 2009; Fedirko et al. Cancer Epidemiol Biomarkers Prev 2009). These authors also observed a decreased labelling of the DNA oxidation marker $8-\mathrm{OH}-\mathrm{dG}$ (induced only by vitamin $\mathrm{D}_{3}$ or calcium alone, but not by the combination) and reduced expression of the marker of long-term proliferation hTERT in the upper part of the crypt (only in the vitamin $\mathrm{D}_{3}+$ calcium group) (Fedirko et al. Cancer Epidemiol Biomarkers Prev 2009; Fedirko et al., Cancer Epidemiol Biomarkers Prev 2010). In addition, the group treated with vitamin $\mathrm{D}_{3}$ alone showed a reduction in the expression of the pro-inflammatory cytokines TNF- $\alpha$, IL- 6 , IL-1 $\beta$ and IL-8, and the pro-inflammatory marker C-reactive protein (Hopkins $\mathrm{MH}$ et al. Cancer Prev Res 2011).

Clearly, there is a need for large and well-designed randomized, double-blind, placebocontrolled clinical studies. Up to now, clinical trials have included mostly elderly people, frequently postmenopausal women, and so, they may not fully reveal the potential action of vitamin D. Additional problems are the lack of an optimal vitamin $\mathrm{D}_{3}$ dose to be used, its possible combination with other agents (calcium), and the long follow-up period that seems recommendable in the case of a disease such as $\mathrm{CRC}$, which probably develops over one or two decades. One promising ongoing trial is the VITamin D and OmegA-3 TriaL (VITAL), a 
study designed to investigate the role of high doses of vitamin $\mathrm{D}_{3}(2,000 \mathrm{IU} / \mathrm{d})$, omega-3 fatty acids $(1 \mathrm{~g} / \mathrm{d})$, and their combination on cancer and cardiovascular diseases in 20,000 initially healthy men and women aged 60 and $65 \mathrm{yr}$ and older, respectively (Okereke and Manson libro azul, Nicholas J 2011 JNCI). In addition, a recent look at the US National Institutes of Health clinical trials website (http://clinicaltrials.gov) showed that more than 1,000 trials are currently underway to assess the effects of vitamin D compounds on cancer and other diseases.

\section{Conclusions and perspectives}

In summary, the vast majority of molecular and genetic data suggests a protective role of vitamin $\mathrm{D}$ against $\mathrm{CRC}$, and epidemiological studies also indicate also that vitamin $\mathrm{D}$ deficiency is linked to high risk of this neoplasia. Globally, the results available on the loss of $V D R$ expression and on the alteration of CYP27B1 and CYP24A1 levels during CRC progression support a role for vitamin D in the prevention and/or in the therapy of early stages rather than in the treatment of advanced cases of this neoplasia. 


\section{Declaration of interest}

The authors declare that there is no conflict of interest that could be perceived as prejudicing the impartiality of this review.

\section{Funding}

The work in the authors' laboratory is supported by Ministerio de Ciencia e Innovación of Spain (SAF2010-18302), Fondo Europeo de Desarrollo Regional-Instituto de Salud Carlos III (RD06/0020/0009) and Comunidad de Madrid.

\section{Acknowledgements}

We thank Prof. Carsten Carlberg for critical reading of part of this review and Robin Rycroft for his valuable assistance in the preparation of the English manuscript. 


\section{References}




\section{Figure legend}

Figure 1. Summary of the antitumoural actions of $1 \alpha, 25$-dihydroxyvitamin $\mathrm{D}_{3}$ in colorectal cancer cells. $1,25(\mathrm{OH})_{2} \mathrm{D}_{3}$ inhibits cell proliferation and angiogenesis, sensitizes to apoptosis, and induces epithelial differentiation and the detoxification metabolism of cultured human CRC cells. 
Table 1. $1 \alpha, 25$-dihydroxyvitamin $D_{3}$ antitumoural actions and target genes in human colorectal cancer cells

\begin{tabular}{|c|c|c|}
\hline Action & Target gene & Reference \\
\hline \multirow[t]{13}{*}{ Proliferation } & $\mathrm{p} 21^{\mathrm{CIP} 1}$ & Evans et al. 1999, Gaschott et al. 2002 \\
\hline & $\mathrm{p} 27^{\mathrm{KIP} 1}$ & Gaschott et al. 2002 \\
\hline & Cyclin A & Fernández-García et al. 2005 \\
\hline & Cyclin F & Pálmer et al. 2003 \\
\hline & GADD45A & Pálmer et al. 2003 \\
\hline & $c-M Y C$ & Pálmer et al. 2001, Meyer et al. 2012 \\
\hline & $c-F O S$ & Meyer et al. 2012 \\
\hline & c-JUN & Pálmer et al. 2003 \\
\hline & TGFBR1 & Chen et al. 2002 \\
\hline & EGFR & Tong et al. 1999 \\
\hline & IGFBP6 & Oh et al. 2001 \\
\hline & CST5 & Álvarez-Díaz et al. 2009 \\
\hline & JMJD3 & Pereira et al. 2011 \\
\hline \multirow[t]{5}{*}{ Apoptosis } & $B A K$ & Díaz et al. 2000 \\
\hline & $B A G-1$ & Barnes et al. 2005 \\
\hline & Gos2 & Pálmer et al. 2003 \\
\hline & Survivin & Liu et al. 2010 \\
\hline & Thymidylate synthase & Liu et al. 2010 \\
\hline \multirow[t]{15}{*}{ Differentiation } & Alkaline phosphatase & Giuliano et al. 1991, Halline et al. 1994, Díaz et al. 2000 \\
\hline & Maltase & Brehier \& Thomasset 1988 \\
\hline & Occludin & Pálmer et al. 2001 \\
\hline & $Z O-1$ & Pálmer et al. 2001 \\
\hline & $Z O-2$ & Pálmer et al. 2001 \\
\hline & Claudin-2 & Fujita et al. 2008 \\
\hline & Claudin-12 & Fujita et al. 2008 \\
\hline & E-cadherin & Pálmer et al. 2001 \\
\hline & Plectin & Pálmer et al. 2003 \\
\hline & Keratin-13 & Pálmer et al. 2003 \\
\hline & Vinculin & Pálmer et al. 2001 \\
\hline & Filamin A & Pálmer et al. 2003 \\
\hline & CST5 & Álvarez-Díaz et al. 2009 \\
\hline & $S P R Y-2$ & Barbáchano et al. 2010 \\
\hline & JMJD3 & Pereira et al. 2011 \\
\hline \multirow[t]{4}{*}{ Angiogenesis } & $H I F-1$ & Ben-Shoshan et al. 2007 \\
\hline & VEGF & Fernández-García et al. 2005 \\
\hline & $T S P-1$ & Fernández-García et al. 2005 \\
\hline & $D K K-4$ & Pendás-Franco et al. 2008 \\
\hline \multirow[t]{6}{*}{ Detoxification } & CYP3A4 & Thummel et al. 2001, Thompson et al. 2002, Pfrunder et al. 2003 \\
\hline & SULT2A1 & Echchgadda et al. 2004 \\
\hline & $M D R-1$ & Pfrunder et al. 2003, Aiba et al. 2005, Fan et al. 2009 \\
\hline & MRP2 & Fan et al. 2009 \\
\hline & MRP3 & McCarthy et al. 2005 \\
\hline & MRP4 & Fan et al. 2009 \\
\hline
\end{tabular}

